\title{
$\mathrm{PH} 105_{\text {actuaidad }}$
}

\section{El Diccionariu de a fala transfiere los resultados de un trabajo de documentación de las hablas fronterizas de la Raya}

El Diccionariu de a fala: lagarteiru, mañegu, valverdeñu fue publicado en septiembre de 2021 y es el resultado de cinco años de trabajo lexicográfico en tres comunidades de la frontera hispano-portuguesa: Eljas, San Martín de Trevejo y Valverde del Fresno (Cáceres). Está enmarcado dentro del proyecto FRONTESPO (Frontera España-Portugal: documentación lingüística y bibliográfica), llevado a cabo desde 2015 por investigadores vinculados a diferentes universidades de toda la Península Ibérica a partir, principalmente, de la realización de entrevistas en el territorio y contando con la participación comunitaria. El diccionario, con sus 13.000 entradas, es el más grande de fala. Se ha publicado en forma de libro, pero también está disponible para la descarga libre.

Irene Sánchez Izquierdo | Dpto. Filología, Comunicación y Documentación, Universidad de Alcalá Miroslav Valeš | Katedra Románských Jazyků, Technical University of Liberec (República Checa)

URL de la contribución <http://www.iaph.es/revistaph/index.php/revistaph/article/view/5048>

La frontera hispano-portuguesa ("la Raya", como se conoce popularmente) es una de las más antiguas, estables y extensas de Europa. Los territorios rayanos, alejados de los centros de poder estatales, han desplegado históricamente muestras de solidaridad e interdependencia. Esto se ha materializado en un estrecho contacto e intercambio entre los dos lados de la frontera, acarreando importantes consecuencias identitarias y sociolingüísticas. Entendida como área fronteriza, la Raya compone un espacio osmótico con identidad propia donde tienen lugar una gran variedad de manifestaciones culturales comunes, compartidas. Una parte muy importante del patrimonio cultural inmaterial -según la Convención de París de la Unesco- son las "tradiciones y expresiones orales, incluido el idioma como vehículo del patrimonio cultural inmaterial" (Unesco 2003, artículo 2).

La movilidad constante y el intercambio entre los dos lados de esta frontera trascendible han convertido la Raya en un espacio donde hoy en día siguen teniendo lugar interesantes fenómenos lingüísticos. Características de la lengua de un lado de la frontera persisten en el otro y viceversa, mostrando cómo la barrera política impuesta desde las capitales no impidió el contacto y la permeabilidad entre ambos universos. Todo esto nos ayuda a contextualizar la existencia de las denominadas hablas fronterizas como el barranqueño, la fala de Xálima (bien de interés cultural en Extremadura desde 2001) o el mirandés, además de otras muchas variedades presentes en multitud de enclaves limítrofes. Sin embargo, son diversos los factores que han ido provocando una intensa transformación y estandarización del paisaje lingüístico fronterizo. La entrada en los hogares de los medios de comunicación como la radio o la televisión contribuyeron a una exposición muy fuerte a las lenguas de referencia estándar (portugués y español). La mejora de las comunicaciones terrestres y la accesibilidad a los servicios de otros puntos de la provincia motivó que los habitantes entrasen en contacto con más frecuencia con sus lenguas vehiculares, más prestigiosas, y fueran modificando su modo de hablar.

La observación de estos fenómenos de cambio, sumados a un escenario de progresiva despoblación y envejecimiento de las localidades rayanas en general, fue el origen de un proyecto de documentación lingüística llevado a cabo por investigadores vinculados a diferentes universidades de toda la Península. Se hacía necesario, en nuestra opinión, un estudio que documentase el estado actual de las hablas fronterizas, con la máxima representación del terreno posible, y que intentase documentar con urgencia el habla de las personas de más 
edad. Como bien hemos dicho, estas especificidades lingüísticas intrínsecas al espacio cultural rayano son parte de su patrimonio cultural inmaterial, estatus que implica la necesidad de desplegar iniciativas para su identificación, difusión y salvaguardia junto con la comunidad de hablantes. Así, nace en el año 2015 el proyecto Frontera España-Portugal: documentación lingüística y bibliográfica (FRONTESPO), al amparo de una subvención concedida por el Ministerio de Economía y Competitividad para el periodo 2015-2017. Este trabajo continúa con el proyecto Frontera hispano-portuguesa: personas, pueblos y palabras (FRONTESPO-3P), financiado por el Ministerio de Ciencia e Innovación, que abarca el periodo 2019-2022.

El objetivo de ambos proyectos es estudiar y documentar exhaustivamente tanto los rasgos lingüísticos como sociolingüísticos de la Raya, y por eso nuestro corpus oral presenta relatos de vida de los hablantes obtenidos a partir de entrevistas semiestructuradas y segmentados por temáticas. En estas conversaciones afloran historias y testimonios que remiten a las formas de vida tradicionales, las costumbres, la historia o la identidad de las diferentes comunidades, relatados en su propia lengua. Podríamos decir que nuestro proyecto es, por esta razón, interdisciplinar: este corpus semiespontáneo es de utilidad para otras áreas como la antropología social, la etnografía, geografía humana, historia, etc. Además, ofrece una visión panorámica sobre elementos patrimoniales de carácter inmaterial comunes a toda la frontera como la práctica del contrabando, migraciones, matrimonios mixtos, fiestas y romerías compartidas, prácticas agrícolas y ganaderas comunitarias, entre otros.

Desde una perspectiva de la cultura basada en el procomún, sostenemos que los proyectos de este tipo deben prestar especial atención al retorno hacia las comunidades investigadas, las comunidades portadoras del patrimonio. Bajo este enfoque, colaboramos con otros proyectos que supongan una devolución directa de las investigaciones sobre el patrimonio de las comunidades, hacia el seno de las mismas. Este ha sido el caso de nuestra participación en el proyecto del Diccionario de a fala en el Valle de Jálama/Xálima (Cáceres), donde se hablan tres variedades de matriz gallego-portuguesa

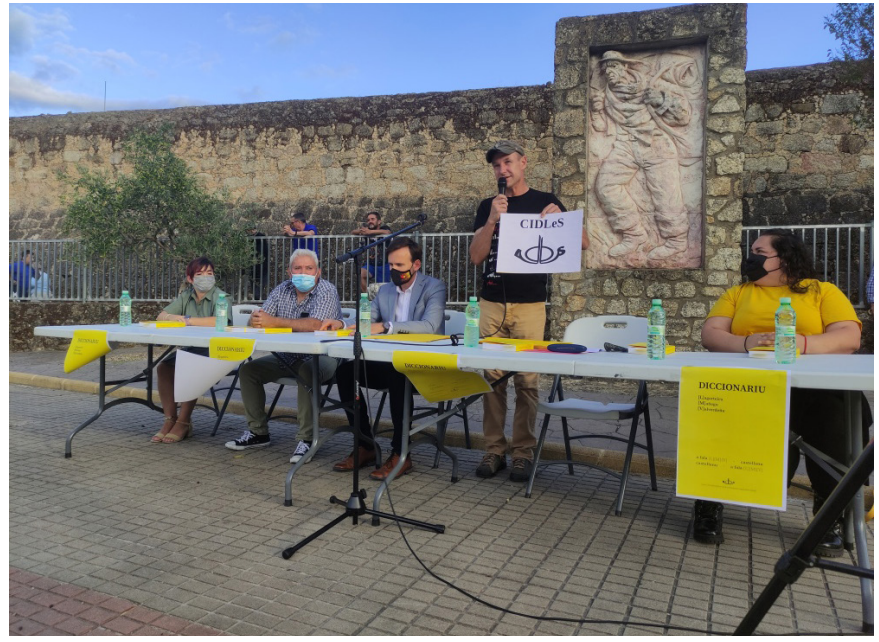

Presentación del diccionario en la localidad de Eljas (Cáceres), con el Monumento al contrabandista al fondo



El Diccionariu fue distribuido gratuitamente entre los miembros de la comunidad y llegó también a las aulas de primaria | fotos Araceli Barroso Lanchares

estrechamente relacionadas entre sí y denominadas con el glotónimo conjunto fala.

El Diccionariu de a fala: lagarteiru, mañegu, valverdeñu fue publicado en septiembre de 2021 y es el resultado de cinco años de trabajo lexicográfico en tres comunidades de la frontera hispano-portuguesa: Eljas, San Martín de Trevejo y Valverde del Fresno. Su compilación ha sido posible gracias a la cooperación entre la Universidad Técnica de Liberec (República Checa) y el Centro Interdisciplinar de Documentação Linguística e Social de 


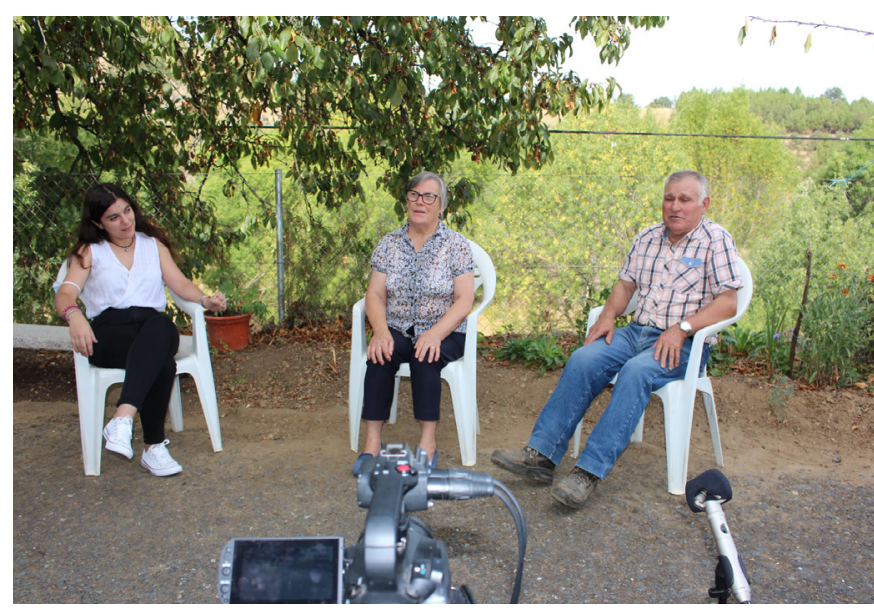

Para comprender el fenómeno lingüístico en su totalidad intentamos localizar y entrevistar hablantes de diferentes generaciones, incluidas las más jóvenes foto FRONTESPO (Alberto Gómez Bautista)

Minde, Portugal. El diccionario es la primera obra lexicográfica publicada que incluye de manera sistemática las tres variedades de la lengua: lagarteiru, mañegu y valverdeñu. Su rasgo más destacable es el respeto a la diversidad de la lengua, ya que documenta las tres variedades sin imponer una sobre las otras y tampoco crea una variedad artificial inexistente.

Con sus 13.000 entradas, es el diccionario más grande de fala. Su metodología se fundamenta en un corpus de datos primarios recopilados en las tres comunidades. Los datos primarios incluyen casi 12 horas de grabaciones transcritas (110.000 palabras), textos en alguna de las tres variedades de fala (115.000 palabras) y una amplia colaboración con la comunidad. Los hablantes de la lengua estuvieron involucrados en todas las fases de la recopilación de datos: grabación de las entrevistas, su transcripción, verificación de lo transcrito, corrección de las primeras versiones del diccionario y finalmente también en la difusión del resultado.

El diccionario se ha publicado en forma de libro, pero también está disponible para la descarga libre en la página de CIDLeS. En la misma página está disponible la base de datos que puede servir a los lingüistas para examinar de manera detallada los aspectos individuales de la lengua. También encontramos en el mismo sitio la versión web del diccionario, cuyo contenido actualmente coincide con la versión en papel, pero contiene material audiovisual complementario. Además, esta versión del diccionario se puede actualizar de manera fácil, y por lo tanto en el futuro reflejará los comentarios y las correcciones que sugieran los hablantes. Es evidente que el trabajo lingüístico no ha terminado con la publicación del libro: la colaboración con la comunidad de hablantes ha sido muy exitosa y todo apunta que estarán dispuestos a participar en otros proyectos relacionados con la descripción y documentación de a fala.

\section{BIBLIOGRAFÍA}

- Unesco [Organización de las Naciones Unidas para la Educación, la Ciencia y la Cultura] (2003) Convención para la Salvaguardia del Patrimonio Cultural Inmaterial. París del 17 de octubre de 2003. Disponible en: https://ich.unesco.org/doc/ src/01852-ES.pdf [Consulta: 12/12/2021] 